\title{
Liver Histopathological Analysis of 24 Postmortem Findings of Patients With COVID-19 in China
}

\author{
Huikuan Chu ${ }^{1 \dagger}$, Li Peng ${ }^{2 \dagger}$, Lilin Hu ${ }^{1}$, Yixin Zhu ${ }^{3}$, Jinfang Zhao ${ }^{4}$, Hua Su ${ }^{5}$, Lin Yao ${ }^{1}$, \\ Qingjing Zhu ${ }^{6}$, Xiu Nie ${ }^{2 *}$, Ling Yang ${ }^{1 *}$ and Xiaohua Hou ${ }^{1 *}$ \\ 1 Division of Gastroenterology, Union Hospital, Tongji Medical College, Huazhong University of Science and Technology, \\ Wuhan, China, ${ }^{2}$ Department of Pathology, Union Hospital, Tongji Medical College, Huazhong University of Science and \\ Technology, Wuhan, China, ${ }^{3}$ Department of Medicine, University of California San Diego, La Jolla, CA, United States, \\ ${ }^{4}$ Center for Life Sciences, Tsinghua University, Beijing, China, ${ }^{5}$ Department of Nephrology, Union Hospital, Tongji Medical \\ College, Huazhong University of Science and Technology, Wuhan, China, ${ }^{6}$ Liver and Infectious Diseases Department, Wuhan \\ Jinyintan Hospital, Wuhan, China
}

Although the pathologic investigation of liver injury was observed in a couple of cases in China, the detailed description of liver histopathologic and ultrastructural changes in a relatively larger series of liver tissues from COVID-19 patients is lacking. Samples from the liver were obtained from 24 COVID-19 cases from February 1 to April 1, 2020. Light microscopy showed that all liver sections had different degrees of liver injury manifested as swelling of the hepatocytes, hepatocellular necrosis, steatosis, lobular inflammation, portal inflammation, dilatation of sinusoids, and so on. SARS-CoV-2 induced liver injury might be independent of pre-existing Schistosoma infection or obstructive cholestasis. Patients combined with respiratory failure had more severe hepatocellular necrosis and male patients were more susceptible to liver injury. Although coronavirus particles or viral inclusions were not detected in the liver tissues for all cases, vacuolar degenerations in hepatocytes, edematous of mitochondria with the disruption of cristae, and expansions of the endoplasmic reticulum were observed. In conclusion, pathologic changes of liver tissues provide us a further understanding of liver injury in COVID-19 patients. Changes in the liver seem to be related to the underlying diseases/conditions.

Keywords: liver histopathological analysis, COVID-19 patients, transmission electron microscopy, edematous of mitochondria, expansions of endoplasmic reticulum

\section{INTRODUCTION}

The Corona Virus Disease 2019 (COVID-19), which is caused by severe acute respiratory syndrome coronavirus 2 (SARS-Cov-2), has been considered as a public health emergency of international concern by the World Health Organization (WHO). Currently, SARS-CoV-2 has spread to over 200 countries and areas with $21,294,845$ confirmed cases, including 761,779 deaths globally until August 16, 2020 (1). COVID-19 mainly affects the lower respiratory tract. Besides, it also induces acute kidney injury and liver dysfunction in some patients (2-5).

On the basis of previous reports from China, a subset of COVID-19 patients had liver impairment with abnormal levels of alanine aminotransferase (ALT) and/or aspartate aminotransferase (AST) accompanied by slightly elevated bilirubin levels during disease progression (6-8). The incidence of liver injury in COVID-19 patients was 
common, especially in some severe and deceased cases (810). The pathologic investigation of liver injury was observed in several studies worldwide (11-15). They centered on the pathologic findings using light microscopy and only one paper described the change of organelles using electron microscopy (15). Besides, pathologic investigation of liver injury was observed only in a couple of cases in China (16), the detailed description of pathologic findings using both light microscopy and transmission electron microscopy observations in a relatively larger series of liver tissues from COVID-19 patients in China is lacking. In this study, we report on our experience of liver findings at autopsy in 24 deceased patients with COVID-19.

\section{METHODS}

\section{Patients}

This study was conducted in accordance with the principles of the Declaration of Helsinki and approved by the Institutional Ethics Board of Union Hospital, Tongji Medical College, Huazhong University of Science and Technology (2020. 00431). Written informed consent was obtained from the next of kin of each enrolled case. According to the World Health Organization Interim Guidance, the diagnosis of COVID-19 was confirmed based on real-time reverse-transcriptase polymerasechain-reaction (RT-PCR) assay for nasal and pharyngeal swab specimens (9). Their electronic medical records, the results of the laboratory, and imaging examinations were all obtained and reviewed. The degree of severity of liver pathological changes was defined using pathologic diagnosis and the grading guideline of common pathological changes after liver transplantation (II) (17) and Scheure scoring system $(18,19)$.

\section{Tissue Sampling and Processing}

Samples from the liver were obtained with ultrasound guidance and percutaneous multiple punctures of the liver from 24 COVID-19 cases with a postmortem interval of $2 \mathrm{~h}$ from February 1 to April 1, 2020. Tissue specimens were fixed in 3.7\% formaldehyde for $48-72 \mathrm{~h}$ before the following procedures. Four micrometer sections were cut and stained with hematoxylineosin. Slides were examined and analyzed by two pathologists blinded to the study.

For EM examination, tissue specimens were fixed in $2.5 \%$ glutaraldehyde for $24-48 \mathrm{~h}$. After $1 \%$ osmic acid post-fixation and gradient dehydration, Epon-embedded, toluidine blue-stained "semi-thin" sections were examined, and selected areas were chosen for thin sections. Thin sections were then cut and stained with uranyl acetate and lead citrate. EM grids were then viewed with a transmission electron microscope (HT-7800; Hitachi, Tokyo, Japan).

\section{Real-Time Reverse Transcription Polymerase Chain Reaction Assay for SARS-COV-2 in Tissue}

Formalin-fixed, paraffin-embedded (FFPE) tissue blocks were used for RNA extraction. Total RNA was extracted using a sample RNA isolation kit (Catalog No. ADx-FF04, fromIde
Biomedical Technology Co., Ltd, Xiamen, China) and a realtime reverse transcriptase polymerase chain reaction (real-time RT-PCR) assay was run on the Mx3000P qPCR system with a 2019-nCoV nucleic acid detection kit (Catalog Z-RR-0479-0225, from Shanghai Zhijiang Biotechnology Co., Ltd, Shanghai, China) according to the manufacturer's protocol.

Two target genes, the RdRp, nucleocapsid protein $(\mathrm{N})$ and E genes, were simultaneously amplified and monitored during the real-time RT-PCR assay. The primers for target 1 (RdRp) were RdRp_SARSr-F $5^{\prime}$-GTGARATGGTCATGTGTGGCGG3', RdRp_SARSr-R 5' -CARATGTTAAASACACTATTAGCATA3', RdRP_SARSr-P1 5'-CCAGGTGGWACRTCATCMGGTGAT GC-3', RdRp_SARSr-P2 5'-CAGGTGGAACCTCATCAGGAG ATGC-3' and E_Sarbeco_F 5'-ACAGGTACGTTAATAGTTAAT AGCGT-3'. The primers for target $2(\mathrm{~N})$ were N_Sarbeco_R $5^{\prime}$-GAGGAACGAGAAGAGGCTTG-3' $3^{\prime}$ and N_Sarbeco_P $5^{\prime}$ ACTTCCTCAAGGAACAACATTGCCA- $3^{\prime}$ and the primers for target 3 (E) were N_Sarbeco_F $5^{\prime}$-CACATTGGCACC CGCAATC-3', E_Sarbeco_R 5'-ATATTGCAGCAGTACGCA CACA-3' and E_Sarbeco_P1 5'-ACACTAGCCATCCTTACTG CGCTTCG-3'. A cycle threshold (Ct) value of 43 or less was defined as a positive, and a $\mathrm{Ct}$ value of more than 43 was defined as a negative. These testing criteria were based on recommendations by the National Institute for Viral Disease Control and Prevention (China) (http://ivdc. chinacdc.cn/kyjz/202001/t20200121_211337. html). Positive and negative controls were included.

\section{Statistical Analysis}

Categorical variables were presented as numbers and percentages. Continuous variables were expressed as median (25th-75th percentile). The relationships of pathologic changes and clinical liver function and inflammatory data were examined using Spearman Rho's $(\rho)$ correlation. Pathologic features among those with and without macrovesicular steatosis/liver fibrosis and among those with and without antiviral intervention/combination therapeutic intervention/combined diseases were compared using Fisher's exact test. Pathologic features among those with different degrees of liver injury and among those with and without antiviral intervention/combination therapeutic intervention/combined diseases were compared using the Mann-Whitney $U$ test. All statistical analyses were performed using SPSS (Statistical Package for the Social Sciences) (version 25.0, IBM Corp, Armonk, NY, USA). A significance level of $P \leq 0.05$ was used for all models (two-sided).

\section{RESULTS}

\section{Clinical Information of the Patients}

The 24 patients with COVID-19 included 16(67\%) males and $8(33 \%)$ females, with an average age of 68.3 years (range, 42-91 years). All cases had positive results for SARS-CoV-2 by nucleic acid testing and characteristic radiologic alterations in lungs. Ten $(41.7 \%)$ patients had a history of hypertension or coronary heart diseases or both. One patient had both coronary heart diseases and diabetes. Six (25\%) patients had 
TABLE 1 | Clinical information of patients with COVID-19 $(N=24)$.

\begin{tabular}{lcc}
\hline Demographics and combined diseases & & Characters \\
\hline Age (years) & & $66(60,78)$ \\
Sex $(n, \%)$ & Female & $8(33 \%)$ \\
Chronic liver diseases $(n, \%)$ & Male & $16(67 \%)$ \\
& With & $4(16.7 \%)$ \\
Diabetes $(n, \%)$ & Without & $20(83.3 \%)$ \\
& With & $1(4.2 \%)$ \\
Hypertension $(n$, \%) & Without & $23(95.8 \%)$ \\
Coronary heart disease $(n, \%)$ & With & $8(33.3 \%)$ \\
& Without & $16(66.7 \%)$ \\
Chronic kidney disease $(n, \%)$ & With & $5(20.8 \%)$ \\
Cancer $(n, \%)$ & Without & $19(79.2 \%)$ \\
& With & $1(4.2 \%)$ \\
& Without & $23(95.8 \%)$ \\
& With & $6(25.0 \%)$ \\
& Without & $18(75.0 \%)$
\end{tabular}

All statistics are presented as median (interquartile range) or $N(\%)$.

TABLE 2 | Summary of laboratory results.

\begin{tabular}{|c|c|c|}
\hline & Initial value & Peak value \\
\hline ALT (U/L) $(N=24)$ & $30(23.5,34.75)$ & $124(46,629.5)$ \\
\hline $\operatorname{AST}(\mathrm{U} / \mathrm{L})(N=24)$ & $42(27.3,58.5)$ & $96(60,817)$ \\
\hline $\mathrm{LDH}(\mathrm{U} / \mathrm{L})(N=24)$ & $465(246.8,591)$ & $614.5(452.8,2,072)$ \\
\hline TBIL (umol/l) $(N=24)$ & $12.2(9.2,21.3)$ & $38.8(20.3,49.1)$ \\
\hline $\operatorname{ALP}(\mathrm{U} / L)(N=24)$ & $71.5(60.8,90.5)$ & $111.5(77,178.8)$ \\
\hline GGT (U/L) $(N=24)$ & $40.5(20.3,65.8)$ & $75.5(38.8,165.5)$ \\
\hline Albumin $(g / l)(N=24)$ & $27.8(25.6,31.8)$ & $21.9(17.3,24.1)$ \\
\hline hs-Tnl (ng/l) $(N=18)$ & $19.55(7.7,61.1)$ & $227.2(49.2,1,876)$ \\
\hline CK-MB (U/L) $(N=16)$ & $14(12,22)$ & $47(26,101.8)$ \\
\hline WBC $(G / L)(N=24)$ & $8.735(5.5,12.4)$ & $21.5(15.3,27.8)$ \\
\hline $\mathrm{LY}(\mathrm{G} / \mathrm{L})(N=24)$ & $0.49(0.33,0.72)$ & $0.24(0.19,0.31)$ \\
\hline $\operatorname{PLT}(\mathrm{G} / \mathrm{L})(N=23)$ & $146(108,233)$ & $33(22,88)$ \\
\hline $\mathrm{Hb}(\mathrm{g} / \mathrm{l})(\mathrm{N}=23)$ & $121(105,144)$ & $70(61,87)$ \\
\hline $\operatorname{Cr}(u m o l / l)(N=24)$ & $68.5(61,98.5)$ & $122.5(92.1,208.4)$ \\
\hline $\mathrm{BUN}(\mathrm{mmol} / \mathrm{l})(\mathrm{N}=24)$ & $7.2(4.9,11.2)$ & $19.6(15.8,32.9)$ \\
\hline D-dimer $(\mathrm{ug} / \mathrm{ml})(N=24)$ & $1.3(0.7,7.8)$ & $8(6.5,8)$ \\
\hline PCT (ng/ml) $(N=22)$ & $0.14(0.11,0.37)$ & $5.7(2.3,25.4)$ \\
\hline $\operatorname{CRP}(m g / l)(N=24)$ & $82.8(45.1,118)$ & $153.4(118.4,173.9)$ \\
\hline
\end{tabular}

All statistics are presented as median (interquartile range).

$A L T$, alanine aminotransferase; ALP, Alkaline phosphatase; AST, aspartate aminotransferase; BUN, blood urea nitrogen; $C K$, creatine kinase; $C r$, creatinine; CRP, C-reactive protein; DM, diabetes; GGT, $\gamma$-glutamyl transpeptidase; Hb, hemoglobin; hs-Tnl, high sensitive troponin l; $L D H$, lactate dehydrogenase; $L Y$, lymphocytes; $P C T$, procalcitonin; PLT, platelet; TBIL, total bilirubin; WBC, white blood cell.

a history of tumor. Three patients had Schistosoma infection and one patient had obstructive cholestasis. One patient had a history of hepatocellular carcinoma. The clinical information and laboratory results are summarized in Tables 1, 2 .

\section{Light Microscopy Findings}

Light microscopy showed that all liver sections had different degrees of liver injury manifested as swelling of the hepatocytes, hepatocellular necrosis, steatosis, lobular inflammation, portal inflammation, dilatation of sinusoids, cholestasis, and fibrosis (Table 3). A detailed assessment of each feature is provided below.

All cases presented with slight to moderate swelling of the hepatocytes (Figure 1A): 13 mild and 11 moderate. The degree of hepatocyte swelling was positively correlated with levels of $\mathrm{LDH}$ at both initial and peak time points, while there was no relationship between the swelling degree of the hepatocytes and therapeutic interventions (Supplementary Tables 1-3).

A previous study reported that about $38 \%$ of the patients dying of COVID-19 had cholestasis (14). Similarly, we found a total of eight from 24 patients (33.3\%) had cholestasis (Figure 1B): 7 cases had mild cholestasis and one case had moderate cholestasis. There was no relationship between liver function tested at the initial time point and cholestasis. However, the levels of ALT, AST, and $\mathrm{LDH}$ tested at peak time point were positively correlated with cholestasis, and cholestasis was also correlated with antiviral therapy combined with ECMO intervention (Supplementary Tables 1-3).

Previous study found that 54-75\% COVID-19 patients presented steatosis $(11,12,14,15)$. Consistently, we found 20 from 24 cases (83.3\%) demonstrated steatosis, 15 cases presented microvesicular steatosis (Figure 1C) and the other 5 presented both microvesicular steatosis and Macrovesicular steatosis. There was no relationship between liver function test at both initial and peak time points and steatosis. Microvesicular steatosis was correlated with antiviral therapy combined with invasive mechanical ventilation intervention, antiviral therapy combined with ECMO intervention and invasive mechanical ventilation (Supplementary Tables 1-3).

28.6-47\% of COVID-19 patients were reported to have hepatic necrosis $(13,15)$, while all cases with different degrees of hepatic necrosis were presented in our study, moderate necrosis was observed in 5 cases and severe hepatocellular necrosis was observed in 10 cases (Figure 1D). The level of total bilirubin at the initial time point was positively related to hepatic necrosis. The level of albumin at the peak time point was negatively related to hepatic necrosis. The levels of ALT, AST, and LDH at the peak time point were positively correlated with hepatic necrosis. Hepatic necrosis was also correlated with antiviral therapy combined with invasive mechanical ventilation intervention (Supplementary Tables 1-3).

Lobular inflammation was observed in all cases and most of them were moderate to severe (Figure 1E). The levels of ALT, AST, LDH, and PCT at the peak time point were positively correlated with lobular inflammation. Lobular inflammation was also correlated with antiviral therapy combined with ECMO intervention (Supplementary Tables 1-3).

Mild to moderate portal inflammation was observed in 23 cases (Figure 1F). The levels of ALT, AST, and LDH at the initial 
TABLE 3 | The pathologic abnormalities of liver using light microscopy observations in 24 cases of deceased patients with COVID-19.

\begin{tabular}{|c|c|c|c|c|c|c|c|c|c|c|}
\hline \multirow[t]{2}{*}{ ID } & \multirow{2}{*}{$\begin{array}{l}\text { Swelling } \\
\text { of the } \\
\text { hepatocytes }\end{array}$} & \multirow{2}{*}{ Cholestasis } & \multirow[t]{2}{*}{$\begin{array}{l}\text { Hepatocellula } \\
\text { necrosis }\end{array}$} & \multicolumn{2}{|c|}{ Steatosis } & \multirow[t]{2}{*}{$\begin{array}{l}\text { Lobular } \\
\text { inflammation }\end{array}$} & \multirow[t]{2}{*}{$\begin{array}{c}\text { Portal } \\
\text { inflammation }\end{array}$} & \multirow[t]{2}{*}{ Fibrosis } & \multirow[t]{2}{*}{ GS } & \multirow{2}{*}{$\begin{array}{l}\text { Dilatation } \\
\text { of } \\
\text { sinusoids }\end{array}$} \\
\hline & & & & $\begin{array}{l}\text { Microvesicular } \\
\text { steatosis } \\
\text { (Relative } \\
\text { area) }\end{array}$ & $\begin{array}{l}\text { Macrovesicular } \\
\text { steatosis }\end{array}$ & & & & & \\
\hline SJ1 & Moderate & Mild & Mild & $60 \%$ & 0 & 2 & 1 & 1 & G2S1 & Moderate \\
\hline SJ2 & Moderate & $\mathrm{N}$ & Mild & $70 \%$ & 0 & 2 & $0-1$ & 0 & G2SO & Mild \\
\hline SJ3 & Moderate & Moderate & Mild & 0 & 0 & 2 & 2 & 1 & G2S1 & Mild \\
\hline SJ4 & Mild & $N$ & Mild & 0 & 0 & $2-3$ & 0 & 1 & $\begin{array}{l}\text { G2- } \\
3 S 1\end{array}$ & Moderate \\
\hline SJ5 & Mild & Mild & Severe & $5 \%$ & 0 & $2-3$ & 1 & 1 & $\begin{array}{l}\text { G2- } \\
3 S 1\end{array}$ & $\mathrm{~N}$ \\
\hline SJ6 & Mild & $\mathrm{N}$ & Mild & $50 \%$ & 0 & 1 & 1 & 0 & G1S0 & Mild \\
\hline SJ7 & Mild & $\mathrm{N}$ & Mild & $10 \%$ & 0 & 1 & 1 & 0 & G1S0 & $N$ \\
\hline SJ8 & Moderate & Mild & Severe & $50 \%$ & 0 & 3 & 2 & 0 & G3S0 & Mild \\
\hline SJ9 & Moderate & $N$ & Mild & $50 \%$ & 0 & 2 & 1 & 0 & G2S0 & Mild \\
\hline SJ10 & Mild & Mild & Severe & $20 \%$ & 0 & 3 & 1 & 0 & G3SO & Moderate \\
\hline SJ11 & Mild & $\mathrm{N}$ & Moderate & $40 \%$ & 0 & 2 & 1 & 0 & G2SO & Moderate \\
\hline SJ12 & Moderate & $N$ & Moderate & $10 \%$ & 0 & 2 & 1 & 0 & G3SO & Moderate \\
\hline SJ13 & Mild & $N$ & Severe & $50 \%$ & 0 & 2 & 1 & 0 & G2S0 & Moderate \\
\hline SJ14 & Mild & $\mathrm{N}$ & Mild & $80 \%$ & $10 \%$ & 2 & 1 & 0 & G2SO & $\mathrm{N}$ \\
\hline SJ15 & Mild & $N$ & Moderate & $30 \%$ & $50 \%$ & $2-3$ & 2 & 3 & $\begin{array}{l}\text { G2- } \\
3 S 3\end{array}$ & Moderate \\
\hline SJ16 & Moderate & Mild & Severe & $60 \%$ & 0 & 3 & 1 & 0 & G3SO & Mild \\
\hline SJ17 & Mild & $N$ & Mild & $70-80 \%$ & $20 \%$ & 2 & 2 & 1 & G2S1 & $\mathrm{N}$ \\
\hline SJ18 & Mild & $N$ & Severe & $80 \%$ & 0 & 3 & 1 & 0 & G3S0 & Mild \\
\hline SJ19 & Mild & $\mathrm{N}$ & Severe & $20 \%$ & 0 & 3 & 1 & 0 & G3S0 & Mild \\
\hline SJ20 & Moderate & $\mathrm{N}$ & Moderate & $70 \%$ & 0 & 3 & 1 & 0 & G3SO & Mild \\
\hline SJ21 & Moderate & Mild & Severe & 0 & 0 & 4 & 2 & 0 & G4SO & Mild \\
\hline SJ22 & Moderate & Mild & Severe & 0 & 0 & 3 & 2 & 1 & G3S1 & $N$ \\
\hline SJ23 & Moderate & $N$ & Severe & $10 \%$ & $60 \%$ & $2-3$ & $1-2$ & 0 & $\begin{array}{l}\text { G2- } \\
3 S 0\end{array}$ & $\mathrm{~N}$ \\
\hline SJ24 & Mild & $N$ & Moderate & $80 \%$ & $10 \%$ & 2 & $1-2$ & 1 & G2S1 & $\mathrm{N}$ \\
\hline
\end{tabular}

ID, identification number; N, no.

time point were positively correlated with portal inflammation while there was no relationship between portal inflammation and therapeutic intervention (Supplementary Tables 1-3).

Eight cases presented with hepatic fibrosis (Figure 1G). There was no relationship between liver function test at both initial and peak time points and hepatic fibrosis. There was also no relationship between hepatic fibrosis and therapeutic intervention (Supplementary Tables 1-3).

Mild to moderate dilatation of sinusoids were observed in 17 cases (Figure 1H). There was no relationship between liver function test at both initial and peak time points and dilatation of sinusoids. Dilatation of sinusoids was correlated with Umifenovir intervention (Supplementary Tables 1-3).

\section{Transmission Electron Microscopy Observations}

Coronavirus particles were also identified in the liver of deceased SARS-CoV-2 patients (16). In order to check whether there were viral particles or inclusions in our patients, we observed the liver tissues using transmission electron microscopy. Inconsistent with previous reports, coronavirus particles or viral inclusions were not detected in the liver tissues for any cases. Vacuolar degenerations in hepatocytes were noted (Figure 2A). Hepatocytes also exhibited marked edematous of mitochondria with the disruption of cristae (Figure 2B). The expansions of the endoplasmic reticulum were also observed (Figure 2C). These indicated that liver injury may be associated with other underlying conditions instead of the direct damage induced by Coronavirus. 


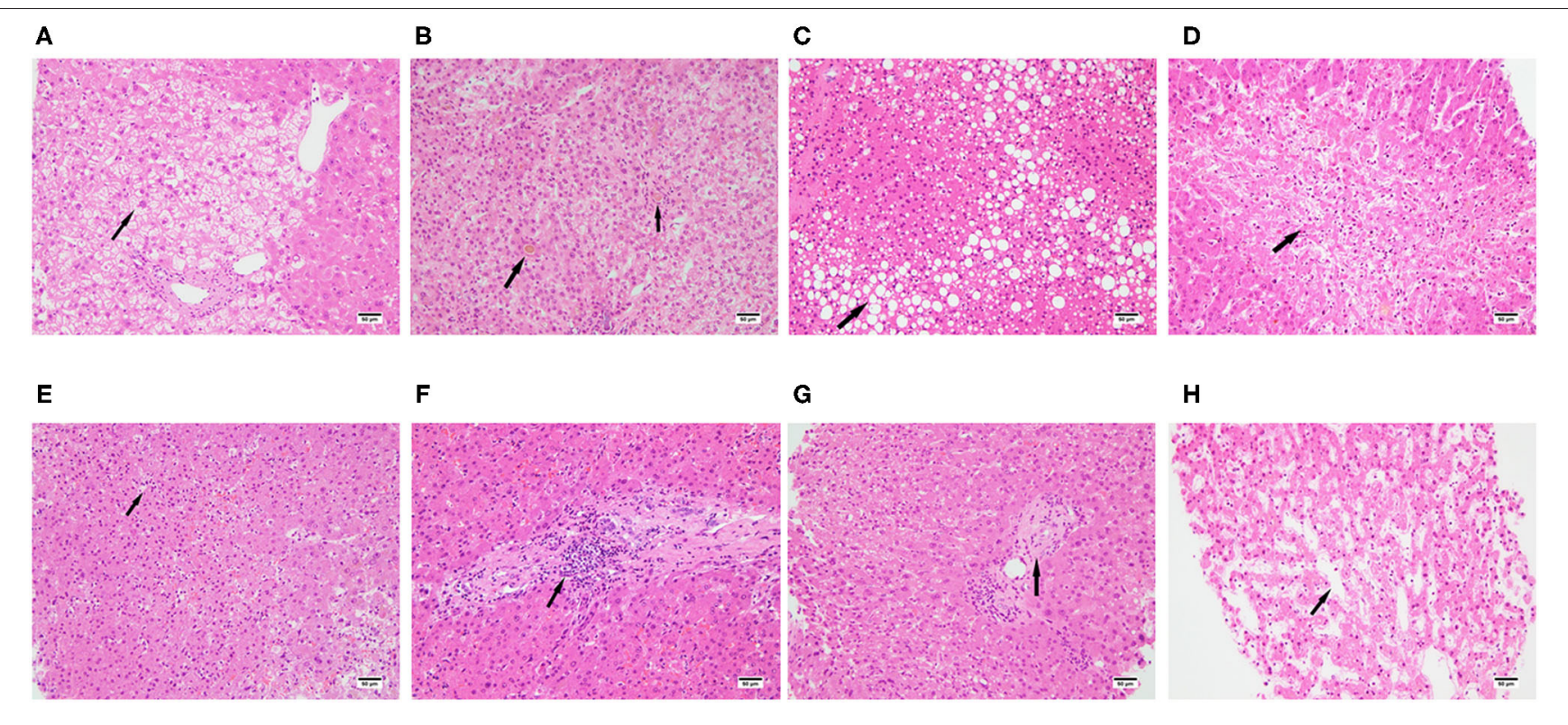

FIGURE 1 | Spectrum of pathologic abnormalities of liver tissues from postmortem of patients with COVID-19. (A) swelling of the hepatocytes, (B) cholestasis, (C) steatosis, (D) hepatocellular necrosis. (E) lobular inflammation, (F) portal inflammation, (G) fibrosis, (H) dilatation of sinusoids, Bars = $50 \mu \mathrm{m}$ (A-D).

A

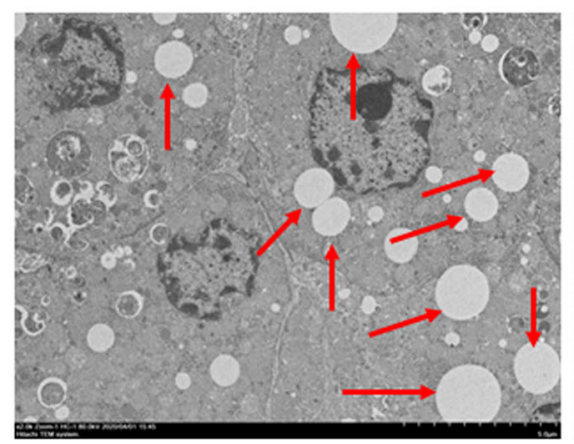

B

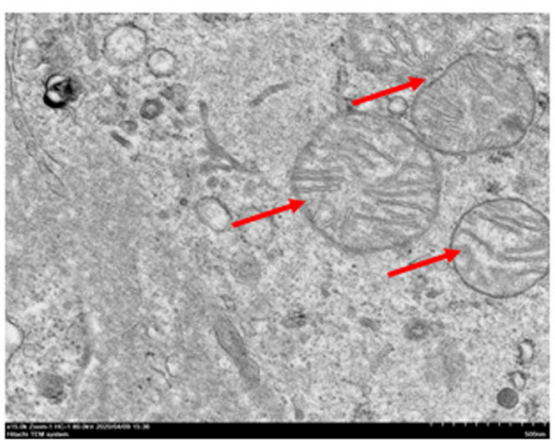

C

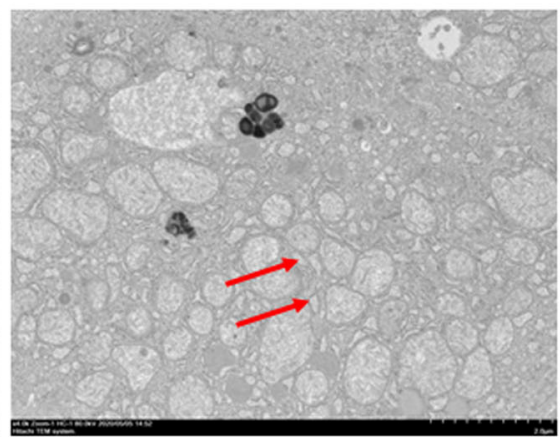

FIGURE 2 | Spectrum of ultrastructural abnormalities of liver tissues from postmortem of patients with COVID-19. (A) vacuolar degenerations in hepatocytes (arrows), (B) edematous of mitochondria and the disruption of cristae (arrows), (C) expansion of endoplasmic reticulum (arrows). Bars $=5 \mu \mathrm{m}$ (A), $500 \mathrm{~nm}$ (B), $2 \mu \mathrm{m}$ (C).

\section{Liver Injury Is Not Associated With SARS-COV-2 Infection in Liver Tissue}

Previous studies speculated that the virus may directly cause liver damage. In order to further confirm this hypothesis, we performed RT-PCR to detect SARS-COV-2 in liver tissues. Surprisingly, tests on the liver tissue from all cases were negative, which is consistent with the result from our transmission electron microscopy observations. This result indicated that liver injury in these cases is not directly caused by SARS-COV-2.

\section{The Degree of Liver Injury Is Associated With Severity of Hypoxemia in COVID-19}

Twenty cases combined with respiratory failure. Among them, nine cases had severe hepatocellular necrosis and five cases had moderate hepatocellular necrosis, while severe hepatocellular necrosis was observed in one patient among the other four patients without respiratory failure. Severe hepatocellular necrosis and lobular inflammation were observed in two patients who were presented with severe respiratory failure and performed ECMO treatment. Moreover, microvesicular steatosis was correlated with invasive mechanical ventilation which is a therapeutic method for severe respiratory failure (Supplementary Table 3). These indicated that hypoxia may contribute to liver injury.

\section{The Degree of Liver Injury Is Not Associated With Combined Diseases in COVID-19}

Three cases combined with Schistosoma infection presented with slight to moderate swelling of the hepatocytes, no or 
TABLE 4 | Exposure to hepatotoxic factors and treatment history.

\begin{tabular}{|c|c|c|c|c|c|c|c|}
\hline ID & $\begin{array}{l}\text { Exposure } \\
\text { to } \\
\text { hepatotoxic } \\
\text { factors }\end{array}$ & Antivirals & Antifungal drugs & Steroid & $\begin{array}{l}\text { Invasive } \\
\text { mechanical } \\
\text { ventilation }\end{array}$ & CRRT & ECMO \\
\hline SJ1 & $\begin{array}{l}\text { Schistosoma } \\
\text { infection }\end{array}$ & Umifenovir & Y & Y & Y & $\mathrm{N}$ & $\mathrm{N}$ \\
\hline SJ2 & $\mathrm{N}$ & Umifenovir, Ribavirin & $\mathrm{N}$ & Y & Y & Y & $\mathrm{N}$ \\
\hline SJ3 & $\begin{array}{l}\text { Obstructive } \\
\text { cholestasis }\end{array}$ & Umifenovir, Ribavirin & $\mathrm{N}$ & Y & $\mathrm{N}$ & $\mathrm{N}$ & $\mathrm{N}$ \\
\hline SJ4 & $\begin{array}{l}\text { Schistosoma } \\
\text { infection }\end{array}$ & Umifenovir, Ribavirin & $\mathrm{N}$ & $\mathrm{N}$ & $\mathrm{N}$ & $\mathrm{N}$ & $\mathrm{N}$ \\
\hline SJ5 & $\mathrm{N}$ & Umifenovir & Y & Y & Y & $\mathrm{N}$ & $N$ \\
\hline SJ6 & $\mathrm{N}$ & Umifenovir, Ribavirin & $\mathrm{N}$ & Y & Y & Y & $\mathrm{N}$ \\
\hline SJ7 & $\mathrm{N}$ & Umifenovir & $\mathrm{N}$ & $\mathrm{N}$ & $\mathrm{N}$ & $\mathrm{N}$ & $\mathrm{N}$ \\
\hline SJ8 & $\mathrm{N}$ & Umifenovir, Ribavirin & Y & Y & Y & $\mathrm{N}$ & $N$ \\
\hline SJ9 & $\mathrm{N}$ & Umifenovir & Y & Y & Y & Y & $\mathrm{N}$ \\
\hline SJ10 & $\mathrm{N}$ & $\mathrm{N}$ & $\mathrm{N}$ & Y & $\mathrm{N}$ & $\mathrm{N}$ & $N$ \\
\hline SJ11 & $\mathrm{N}$ & $\begin{array}{l}\text { Ganciclovir, Oseltamivir, } \\
\text { Umifenovir }\end{array}$ & $\mathrm{N}$ & Y & Y & $\mathrm{N}$ & $\mathrm{N}$ \\
\hline SJ12 & $\mathrm{N}$ & Umifenovir, Interferon $\alpha 2 \beta$ & Y & Y & Y & $\mathrm{N}$ & $N$ \\
\hline SJ13 & $\mathrm{N}$ & $\begin{array}{l}\text { Oseltamivir, Umifenovir, } \\
\text { Ribavirin, Interferon } \alpha 2 \beta \text {, } \\
\text { Lopinavir and Ritonavir }\end{array}$ & Y & Y & Y & $\mathrm{N}$ & $N$ \\
\hline SJ14 & $\mathrm{N}$ & $\begin{array}{l}\text { Interferon } \alpha 2 \beta \text {, Ganciclovir, } \\
\text { Ribavirin }\end{array}$ & $\mathrm{N}$ & Y & Y & $\mathrm{N}$ & N \\
\hline SJ15 & $\mathrm{N}$ & Umifenovir, Ribavirin & Y & Y & Y & $\mathrm{N}$ & $\mathrm{N}$ \\
\hline SJ16 & $\mathrm{N}$ & Umifenovir, Ribavirin & Y & Y & Y & $\mathrm{N}$ & $N$ \\
\hline SJ17 & $\mathrm{N}$ & Umifenovir & Y & Y & Y & Y & $\mathrm{N}$ \\
\hline SJ18 & $\mathrm{N}$ & Umifenovir, Ribavirin & Y & Y & Y & Y & $N$ \\
\hline SJ19 & $\mathrm{N}$ & Umifenovir, Ribavirin & Y & Y & Y & $\mathrm{N}$ & $\mathrm{N}$ \\
\hline SJ20 & $\mathrm{N}$ & Umifenovir & Y & $\mathrm{N}$ & Y & Y & $N$ \\
\hline SJ21 & $\mathrm{N}$ & $\begin{array}{l}\text { Umifenovir, Ribavirin, } \\
\text { Interferon } \alpha 2 \beta\end{array}$ & Y & Y & Y & Y & Y \\
\hline SJ22 & $\mathrm{N}$ & Ribavirin & Y & Y & Y & $\mathrm{Y}$ & Y \\
\hline SJ23 & $\mathrm{N}$ & $\begin{array}{l}\text { Interferon } \alpha 2 \beta \text {, Umifenovir, } \\
\text { Ribavirin }\end{array}$ & Y & Y & Y & $\mathrm{N}$ & $\mathrm{N}$ \\
\hline SJ24 & $\begin{array}{l}\text { Schistosoma } \\
\text { infection }\end{array}$ & Ribavirin, Ganciclovir & $\mathrm{N}$ & Y & Y & $\mathrm{Y}$ & $\mathrm{N}$ \\
\hline
\end{tabular}

CRRT, continuous renal replacement therapy; ECMO, Extracorporeal Membrane Oxygenation; ID, identification number; N, no; Y, yes.

mild cholestasis, and mild to moderate hepatocellular necrosis. One case combined with obstructive cholestasis presented with moderate swelling of the hepatocytes, moderate cholestasis, and mild hepatocellular necrosis (Table 4). These results indicated that SARS-CoV-2 induced liver injury might be independent of pre-existing Schistosoma infection or obstructive cholestasis. Moreover, we analyzed the relationships between combined diseases and liver injury and found that there was no relationship between them (Supplementary Table 4).

\section{DISCUSSION}

In the present study, we report the liver histopathologic, ultrastructural, and RT-PCR findings from biopsies of 24 patients who died from respiratory failure or circulatory failure due to
COVID-19. This is the first detailed report of liver pathologic presentations using both light microscopy and transmission electron microscopy observations from a large series of liver tissues in patients with SARS-CoV-2 infection in China. Our biopsy study demonstrates the range of abnormalities present and the specific hepatocellular necrosis that might be induced by hypoxia in COVID-19 patients, and thus may provide important information for future clinicopathologic studies in severely ill patients with COVID-19 infection and liver injury. We observed mild to moderate cholestasis. This is in accordance with mechanisms known for SARS-CoV-2 infection via angiotensinconverting enzyme II (ACE2) on bile duct epithelial cells in the liver (20). We also show findings that suggest distinct mechanisms of this novel coronavirus infection, significant hepatocellular necrosis. Thus, these pathologic observations 
may provide a basis for further understanding of COVID19.

The detailed description of pathologic findings has been described by several studies. Hepatic necrosis, portal tract inflammation, lobular inflammation, steatosis, increased number of histiocytes and megakaryocytes and platelet-fibrin microthrombi were described by Zhao et al. (15). Bradley et al. demonstrated the presence of acute congestion, centrilobular necrosis and mild periportal lymphocytic inflammation (13). Sonzogni et al. reported fibrosis, mild to moderate lobular inflammation, mild portal inflammation, parenchymal confluent necrosis, steatosis, vascular thrombosis, vascular alterations including portal vein parietal fibrosis, herniated portal vein in periportal parenchyma and periportal abnormal vessels (11). Lagana et al. found lobular necroinflammation and portal inflammation, lobular apoptosis, steatosis, and cholestasis (14). Diaz et al. wrote a meta-analysis to summarize the presentations including hepatic steatosis, congestion of hepatic sinuses and necrosis, vascular thrombosis and other vascular alterations, fibrosis, Kupffer cell proliferation or hyperplasia, portal and lobular inflammation (12). We found similar presentations including hepatocellular necrosis, cholestasis, steatosis, lobular inflammation, portal inflammation and fibrosis. Moreover, we found swelling of the hepatocytes, and dilatation of sinusoids.

Vascular thrombosis was described in several articles $(11,12$, 15), while we did not find vascular thrombosis in our paper. This may be related with a lower level of platelets and D-dimer value compared to previous study. Only five patients had a low level of platelets $(<100 \mathrm{G} / \mathrm{L})$ in the study of Sonzogni et al. (11), while a total of $19 / 23(82.6 \%)$ patients had a low level of platelets $(<100 \mathrm{G} / \mathrm{L})$ with an average of $33 \mathrm{G} / \mathrm{L}$ at peak time point in our paper. The average value of D-dimer was $8 \mathrm{ug} / \mathrm{ml}$ $(80 \mathrm{ng} / \mathrm{dl})$ in our paper, which is lower than previous report with $96 \%$ patients having a very high value of $\mathrm{D}$-dimer values $\geq 500$ $\mathrm{ng} / \mathrm{dL}$ (11).

In this study, we did not detect viral RNA or viral particles from liver tissues for all patients. Lagana et al. identified viral RNA in some liver tissue samples, but there was no significant correlations between PCR positivity and any histologic finding (14). Thus, we conclude that liver damage was not caused by virus directly. We observed significant hepatocellular necrosis, and the change of ultrastructural features of hepatocytes, such as vacuolar degenerations, edematous of mitochondria with the disruption of cristae and the expansions of endoplasmic reticulum in cases without viral particles or inclusions detected in their liver tissues. These indicate that hepatocellular injury may be induced by other mechanisms instead of SARS-CoV-2 infection directly. Hypoxia, presenting as one of the common symptoms in COVID-19 patients, may be related to liver injury (21). Our data confirmed that more patients with severe hepatocellular necrosis had respiratory failure compared to patients with mild or moderate hepatocellular necrosis. Moreover, microvesicular steatosis was correlated with invasive mechanical ventilation which is a therapeutic method for severe respiratory failure. We also found that the level of PCT at the peak time point was positively correlated with lobular inflammation. Thus, systemic inflammation induced by virus and hypoxia which is induced by respiratory failure might contribute to liver injury. Moreover, organ failure may be also related with liver injury, as invasive mechanical ventilation and/or ECMO intervention which were therapeutic methods for organ failure were related with liver injury. Besides, the adverse effects of some drugs may be another factor to cause liver injury $(22,23)$. In our study, antiviral drugs were widely used for our patients, and patients treated with two or more kinds of antiviral drugs seem to have more severe hepatocyte necrosis and liver injury (Table 3 ). In addition, patients who had a history of antifungal drugs usage seem to have more severe hepatocyte necrosis and liver injury (Table 3).

Our data confirmed that $41.7 \%$ of the patients with liver injury presented as severe hepatocellular necrosis, which was higher than those found in previous studies $(24,25)$. This might be related to the severity of the COVID-19 patients. About $80 \%$ of the patients were nonsevere patients in previous studies $(24,25)$, while all the patients in our study were severe cases and deceased in the end. Besides, the mechanisms of liver injury might be different with different degrees of severity of COVID-19 infection.

In this study, we did not detect viral RNA, viral particles, or inclusions from liver tissues for all patients, which is inconsistent with previous studies $(11,14-16)$. It is probable that there was no virus in the liver tissue for these patients. It is also possible that the virus was cleared already, and the clearance of the virus may be related to different stages of disease progression.

In summary, we observed pathologic changes of liver injury using light microscopy and transmission electron microscopy in some deceased patients with COVID-19. We described the liver injury patterns and the severity of liver injury and found that $41.7 \%$ of the patients had severe hepatocyte necrosis. Liver injury may be related with systemic inflammation and hypoxia induced by COVID-19 infection, hepatotoxic effects from antifungal agents and antiviral therapy, and organ failure that needs invasive mechanical ventilation and/or ECMO intervention. However, there are still some limitations for our study, such as a relatively small number of cases. Further studies with a larger number of cases are needed for more comprehensive understandings of liver injury in COVID19 patients.

\section{DATA AVAILABILITY STATEMENT}

The original contributions presented in the study are included in the article/Supplementary Material, further inquiries can be directed to the corresponding author/s.

\section{ETHICS STATEMENT}

The studies involving human participants were reviewed and approved by the Institutional Ethics Board of Union 
Hospital, Tongji Medical College, Huazhong University of Science and Technology. The next of kin of each enrolled patient/participant provided their written informed consent to participate in this study. Written informed consent was obtained from the individual(s) for the publication of any potentially identifiable images or data included in this article.

\section{AUTHOR CONTRIBUTIONS}

HC: conceptualization, methodology, validation, formal analysis, investigation, and writing-original draft. LP: methodology, validation, formal analysis, investigation, and visualization. $\mathrm{LH}$ and JZ: methodology, validation, and formal analysis. YZ: methodology, formal analysis, and language correction. HS: formal analysis, investigation, and visualization. LYao and QZ: methodology, validation, formal analysis, and investigation. $\mathrm{XN}$, LYan, and $\mathrm{XH}$ : conceptualization, investigation, resources, writing-review and editing, and supervision. All authors contributed to the article and approved the submitted version.

\section{REFERENCES}

1. World Health Organization. Weekly Operational Update on COVID-19 25 September 2020. (2000). Available online at: https://www.who.int/docs/ default-source/coronaviruse/weekly-updates/wou-25-september-2020-forcleared.pdf (accessed September 27, 2020).

2. Wang D, Hu B, Hu C, Zhu F, Liu X, Zhang J, et al. Clinical characteristics of 138 hospitalized patients with 2019 novel coronavirus-infected pneumonia in Wuhan, China. JAMA. (2020) 323:1061-9. doi: 10.1001/jama.2020.1585

3. Yang X, Yu Y, Xu J, Shu H, Xia J, Liu H, et al. Clinical course and outcomes of critically ill patients with SARS-CoV-2 pneumonia in Wuhan, China: a single-centered, retrospective, observational study. Lancet Respir Med. (2020) 8:475-81. doi: 10.1016/S2213-2600(20)30079-5

4. Cui Y, Tian M, Huang D, Wang X, Huang Y, Fan L, et al. A 55-day-old female infant infected with 2019 novel coronavirus disease: presenting with pneumonia, liver injury, and heart damage. J Infect Dis. (2020) 221:1775-81. doi: 10.1093/infdis/jiaa113

5. Special Expert Group for Control of the Epidemic of Novel Coronavirus Pneumonia of the Chinese Preventive Medicine Association. An update on the epidemiological characteristics of novel coronavirus pneumonia COVID-19. Zhonghua Liu Xing Bing Xue Za Zhi. (2020) 41:139-44. doi: $10.3760 / \mathrm{cma}$.j.issn.0254-6450.2020.02.002

6. Xu XW, Wu XX, Jiang XG, Xu KJ, Ying LJ, Ma CL, et al. Clinical findings in a group of patients infected with the 2019 novel coronavirus (SARS-Cov2) outside of Wuhan, China: retrospective case series. BMJ. (2020) 368:m606. doi: 10.1136/bmj.m606

7. Shi H, Han X, Jiang N, Cao Y, Alwalid O, Gu J, et al. Radiological findings from 81 patients with COVID-19 pneumonia in Wuhan, China: a descriptive study. Lancet Infect Dis. (2020) 20:425-34. doi: 10.1016/S1473-3099(20) 30086-4

8. Guan WJ, Ni ZY, Hu Y, Liang WH, Ou CQ, He JX, et al. Clinical characteristics of Coronavirus Disease 2019 in China. N Engl J Med. (2020) 382:1708-20. doi: 10.1056/NEJMoa2002032

9. Huang C, Wang Y, Li X, Ren L, Zhao J, Hu Y, et al. Clinical features of patients infected with 2019 novel coronavirus in Wuhan, China. Lancet. (2020) 395:497-506. doi: 10.1016/S0140-6736(20)30183-5

10. Zhang B, Zhou X, Qiu Y, Song Y, Feng F, Feng J, et al. Clinical characteristics of 82 cases of death from COVID-19. PLoS ONE. (2020) 15:e0235458. doi: 10.1371 /journal.pone. 0235458

\section{FUNDING}

The study was supported by Urgent projects of scientific and technological research on COVID-19 funded by Hubei province (No. 2020FCA014 to XH), Key Special Projects of the Hubei Provincial Department of Science and Technology (No. 2019ACA133 to LY), National Natural Science Foundation of China (No. 82072333 to XN), and the China Postdoctoral Science Foundation (No. 2020M670289 and 2020T130065ZX to JZ).

\section{ACKNOWLEDGMENTS}

The authors appreciate the language correction and technical support from Dr. Brant Wang from Department of Pathology, Inova Fairfax Hospital, 3300 Gallows Road, Falls Church, VA, USA.

\section{SUPPLEMENTARY MATERIAL}

The Supplementary Material for this article can be found online at: https://www.frontiersin.org/articles/10.3389/fmed. 2021.749318/full\#supplementary-material

11. Sonzogni G, Previtali M, Seghezzi M, Grazia Alessio A, Gianatti L, Licini D, et al. Liver histopathology in severe COVID 19 respiratory failure is suggestive of vascular alterations. Liver Int. (2020) 40:2110-6. doi: 10.1111/liv.14601

12. Diaz LA, Idalsoaga F, Cannistra M, Candia R, Cabrera D, Barrera F, et al. High prevalence of hepatic steatosis and vascular thrombosis in COVID-19: a systematic review and meta-analysis of autopsy data. World J Gastroenterol. (2020) 26:7693-706. doi: 10.3748/wjg.v26.i48.7693

13. Bradley BT, Maioli H, Johnston R, Chaudhry I, Fink SL, Xu H, et al. Histopathology and ultrastructural findings of fatal COVID-19 infections in Washington State: a case series. Lancet. (2020) 396:320-32. doi: 10.1016/S0140-6736(20)31305-2

14. Lagana SM, Kudose S, Iuga AC, Lee MJ, Fazlollahi L, Remotti HE, et al. Hepatic pathology in patients dying of COVID-19: a series of 40 cases including clinical, histologic, and virologic data. Mod Pathol. (2020) 33:214755. doi: 10.1038/s41379-020-00649-x

15. Zhao CL, Rapkiewicz A, Maghsoodi-Deerwester M, Gupta M, Cao W, Palaia T, et al. Pathological findings in the postmortem liver of patients with coronavirus disease 2019 (COVID-19). Hum Pathol. (2021) 109:59-68. doi: 10.1016/j.humpath.2020.11.015

16. Wang Y, Liu S, Liu H, Li W, Lin F, Jiang L, et al. SARS-CoV-2 infection of the liver directly contributes to hepatic impairment in patients with COVID-19. J Hepatol. (2020) 73:807-16. doi: 10.1016/j.jhep.2020.05.002

17. National hepatobiliary tumor and Transplantation Pathology Collaboration Group. Pathologic diagnosis and grading guideline of common pathological changes after liver transplantation (II). Prac J Organ Transplant. (2015) 3:1-7.

18. Desmet VJ, Gerber M, Hoofnagle JH, Manns M, Scheuer PJ. Classification of chronic hepatitis: diagnosis, grading and staging. Hepatology. (1994) 19:151320. doi: 10.1002/hep.1840190629

19. Scheuer PJ. Classification of chronic viral hepatitis: a need for reassessment. $J$ Hepatol. (1991) 13:372-4. doi: 10.1016/0168-8278(91)90084-O

20. Chai X, Hu L, Zhang Y, Han W, Lu Z, Ke A, et al. Specific ACE2 expression in cholangiocytes may cause liver damage after 2019-nCoV infection. bioRxiv. (2020) doi: 10.1101/2020.02.03.931766

21. Yang L, Wang W, Wang X, Zhao J, Xiao L, Gui W, et al. Creg in hepatocytes ameliorates liver ischemia/reperfusion injury in a TAK1-dependent manner in mice. Hepatology. (2019) 69:294-313. doi: 10.1002/hep.30203

22. Yancheva N, Tzonev R. A case of late presentation of darunavirrelated cholestatic hepatitis. Int J STD AIDS. (2019) 30:620-2. doi: $10.1177 / 0956462419826723$ 
23. Marty FM, Vidal-Puigserver J, Clark C, Gupta SK, Merino E, Garot $\mathrm{D}$, et al. Intravenous zanamivir or oral oseltamivir for hospitalised patients with influenza: an international, randomised, double-blind, double-dummy, phase 3 trial. Lancet Respir Med. (2017) 5:135-46. doi: 10.1016/S2213-2600(16)30435-0

24. Cai Q, Huang D, Yu H, Zhu Z, Xia Z, Su Y, et al. COVID-19: abnormal liver function tests. J Hepatol. (2020) 73:566-74. doi: 10.1016/j.jhep.2020.04.006

25. Ji D, Qin E, Xu J, Zhang D, Cheng G, Wang Y, et al. Non-alcoholic fatty liver diseases in patients with COVID-19: a retrospective study. J Hepatol. (2020) 73:451-3. doi: 10.1016/j.jhep.2020.03.044

Conflict of Interest: The authors declare that the research was conducted in the absence of any commercial or financial relationships that could be construed as a potential conflict of interest.
Publisher's Note: All claims expressed in this article are solely those of the authors and do not necessarily represent those of their affiliated organizations, or those of the publisher, the editors and the reviewers. Any product that may be evaluated in this article, or claim that may be made by its manufacturer, is not guaranteed or endorsed by the publisher.

Copyright (C) 2021 Chu, Peng, Hu, Zhu, Zhao, Su, Yao, Zhu, Nie, Yang and Hou. This is an open-access article distributed under the terms of the Creative Commons Attribution License (CC BY). The use, distribution or reproduction in other forums is permitted, provided the original author(s) and the copyright owner(s) are credited and that the original publication in this journal is cited, in accordance with accepted academic practice. No use, distribution or reproduction is permitted which does not comply with these terms. 